\title{
PENGEMBANGAN SISTEM INFORMASI PENJUALAN DAN PERAMALAN JUAL BELI MENGGUNAKAN METODE WEIGHTED MOVING AVERAGE (Studi Kasus Toko Emas Maju Sari Kota Malang)
}

\author{
Hendra Pradibta ${ }^{1}$, Aulia Umar Nur al Saffa ${ }^{2}$ \\ Program Studi Teknik Informatika, Jurusan Teknologi Informasi, Politeknik Negeri Malang \\ JL. Soekarno-Hatta No. 9 Malang 65141, Indonesia \\ ${ }^{1}$ ndropradibta@gmail.com, ${ }^{2}$ auliaumarnas@gmail.com
}

\begin{abstract}
Abstrak
Dengan banyaknya transaksi membuat dibutuhkan sistem yang menunjang transaksi pada toko emas Maju Sari. Sistem informasi penjualan penting digunakan agar dapat menunjang kinerja pada toko. Penentuan jumlah stok yang mengacu pada peramalan jumlah penjualan dan pembelian membuat toko mendapatkan informasi yang tepat. Tujuan dari pembuatan sistem informasi ini adalaha menganalisa kinerja toko dan analisa metode peramalan weighted moving average secara manual kedalam sistem informasi agar lebih praktis, dengan menggunakan VB.Net sebagai bahasa pemrograman dan SQL Server sebagai database. Setelah melakukan observasi pada toko emas Maju Sari, didapat alur proses transaksi dan hasil historis penjualan barang (kalung, liontin, anting, giwang, gelang, dan cincin) pada tahun 2012 hingga 2014 untuk dianalisa. Dari metode peramalan dapat dihitung forcast error-nya dengan menggunakan metode mean absolute deviation dan mean absolute percent. Dari sistem informasi yang dikembangkan dan analisa yang telah dilakukan, dapat disimpulkan bahwa sistem berjalan sesuai dengan alur proses transaksi pada toko emas serta mengetahui peramalan atau prediksi penjualan dan pembelian pada masa mendatang. Sehingga dapat membantu toko emas Maju Sari untuk menentukan jumlah stok barang untuk penjualan kedepan.
\end{abstract}

Kata kunci: Sistem Informasi, Penjualan, Peramalan, Weighted Moving Average

\section{Pendahuluan}

Dengan seiring perkembangan zaman, peminat manusia untuk mengoleksi perhiasan tetaplah tinggi. Sehingga, masih banyak toko emas yang ada di kotakota besar maupun kecil yang tetap berdiri dan berkembang. Namun yang terjadi banyak usaha penjualan emas sering mengalami kerugian di bagian pencatatan laporan keuangannya.

Pelayanan transaksi yang masih menggunakan cara manual menyebabkan kurang efisiennya kegiatan dalam transaksi maupun pembukuan laporan keuangan. Struk atau bukti pembayaran yang ditulis secara manual bisa hilang apabila ada keteledoran karyawan maupun pemilik yang merekap data transaksi. Efisiensi waktu yang kurang, pada dasarnya toko emas yang menggunakan sistem manual setiap hari sebelum toko tutup wajib melakukan pencatatan laporan keuangan.

Selain pencatatan semua kegiatan yang masih manual, pemilik toko juga masih juga susah untuk menentukan kapan seharusnya menambah stok atau mengurangi stok dari supplier. Karena pembeli dalam melakukan pembelian jenis barang tertentu cenderung tidak rata, melainkan ada naik turun dari kegitan transaksi. Dengan begitu akan menimbulkan pertanyaan, apakah pembeli emas memiliki pola tertentu dalam melakukan penjualan dan pembelian?
Dan apakah ada perkiraan mengenai penjualan dan pembelian emas oleh konsumen dalam waktu kedepan?

Peramalan atau prediksi penjualan dan pembelian dapat menentukan jumlah stok barang untuk bulan berikutnya sesuai dengan hasil peramalan. Karena selama ini, permasalahan yang ada, pemilik toko susah memprediksi keperluan stok untuk bulan berikutnya dan hanya menambah jumlah stok dengan menggunakan semua hasil uang yang didapat pada bulan sebelumnya.

Dengan adanya permasalahan yang ada didalam toko emas (disini studi kasus dari toko emas maju sari) maka akan perlunya sistem informasi jual beli untuk mempermudah dan membantu efisiensi waktu dalam kegiatan transaksi di toko tersebut. Selain bertujuan untuk memudahkan proses jual beli, sistem juga membutuhkan prediksi berapa jumlah barang yang akan laku pada waktu tertentu yang akan datang. Oleh karena itu penulis membuat sistem tersebut dan melakukan penelitian yang bisa memprediksi tentang jumlah barang yang akan dijual atau dibeli oleh konsumen pada waktu tertentu dengan mengacu berdasarkan data transaksi sebelumnya, menggunakan metode weighted moving average. 


\section{Landasan Teori}

\subsection{Sistem Informasi}

Sistem Informasi merupakan kesatuan elemen-elemen yang saling berinteraksi secara sistematis dan teratur untuk menciptakan dan membentuk aliran informasi yang akan mendukung pembuatan keputusan dan melakukan kontrol terhadap jalannya perusahaan (Budi Sutedjo, 2002).

\subsection{Sistem Informasi Akuntansi}

Sistem Informasi Akuntansi (SIA) adalah sebuah sistem informasi yang menangani segala sesuatu yang berkenaan dengan Akuntansi. Akuntansi sendiri sebenarnya adalah sebuah sistem informasi dengan fungsi yang terpenting diantaranya (Lilis Puspitawati, 2011):

1. Mengumpulkan dan menyimpan data tentang aktivitas dan transaksi.

2. Memproses data menjadi informasi yang dapat digunakan dalam proses pengambilan keputusan.

3. Melakukan kontrol secara tepat terhadap aset organisasi.

4. Subsistem SIA memproses bagian transaksi keuangan dan transaksi non-keuangan yang secara langsung mempengaruhi pemrosesan transaksi keuangan.

SIA terdiri dari 3 subsistem, diantaranya:

1. Sistem pemrosesan transaksi mendukung proses operasi bisnis harian .

2. Sistem buku besar atau pelaporan keuangan.

3. Sistem penutupan dan pembalikan.

Batasan SIA pada sistem yang akan dibangun meliputi sistem pemrosesan transaksi dan sistem buku besar atau pelaporan keuangan secara sederhana sesuai dengan kebutuhan studi kasus yang akan diteliti.

\subsection{Weighted Moving Average}

Weighted Moving Average merupakan metode peramalan bagian dari metode peramalan forecasting. Forecasting adalah peramalan atau perkiraan mengenai sesuatu yang belum terjadi. Ramalan yang dilakukan pada umumnya akan berdasarkan data yang terdapat di masa lampau yang dianalisis dengan mengunakan metode-metode tertentu. Forecasting diupayakan dibuat dapat meminimumkan pengaruh ketidakpastian tersebut, dengan kata lain bertujuan mendapatkan ramalanyang bisa meminimumkan kesalahan meramal (forecast error) yang biasanya diukur dengan Mean Absolute Deviation, Absolute Error, dan sebagainya. Peramalan merupakan alat bantu yang sangat penting dalam perencanaan yang efektif dan efisien (Subagyo, 1986).

Peramalan permintaan memiliki karakteristik tertentu yang berlaku secara umum. Karakteristik ini harus diperhatikan untuk menilai hasil suatu proses peramalan permintaan dan metode peramalan yang digunakan. Karakteristik peramalan yaitu faktor penyebab yang berlaku di masa lalu diasumsikan akan berlaku juga di masa yang akan datang, dan peramalan tak pernah sempurna, permintaan aktual selalu berbeda dengan permintaan yang diramalkan (Baroto, 2002).

Penggunaan berbagai model peramalan akan memberikan nilai ramalan yang berbeda dan derajat dari galat ramalan (forecast error) yang berbeda pula. Seni dalam melakukan peramalan adalah memilih model peramalan terbaik yang mampu mengidentifikasi dan menanggapi pola aktivitas historis dari data. Model-model peramalan dapat dikelompokan ke dalam dua kelompok utama, yaitu metode kualitatif dan metode kuantitatif. Metode kuantitatif dikelompokkan ke dalam dua kelompok utama, yaitu intrinsik dan ekstrinsik.

Model kuantitatif intrinsik sering disebut sebagai model-model deret waktu (time series model). Model deret waktu yang populer dan umum diterapkan dalam peramalan permintaan adalah ratarata bergerak (moving averages), pemulusan eksponensial (exponential smoothing), dan proyeksi kecenderungan (trend projection). Model kuantitatif ekstrinsik sering disebut juga sebagai model kausal, dan yang umum digunakan adalah model regresi (regression causal model) (Gaspersz, 2002).

Rata-rata bergerak adalah salah satu metode peramalan yang menggunakan rata-rata periode terakhir data untuk meramalkan periode berikutnya. Moving average dibedakan menjadi 2 yaitu single moving average dan weight moving average. Berikut penjelasan dari single moving average dan weight moving average:

1. Single Moving Average

Single moving average (rata-rata bergerak sederhana) merupakan metode yang bermanfaat apabila jika diasumsikan bahwa permintaan pasar tetap stabil. Rumus dibawah merupakan persamaan dari metode tersebut.

$$
M=\frac{\sum \text { Permintaan pada periode } n \text { sebelumnya }}{n}
$$

2. Weigted Moving Average

Weight moving average (rata-rata bergerak tertimbang) merupakan metode yang bermanfaat apabila ada pola atau trend yang dapat dideteksi, timbangan bisa digunakan untuk menempatkan lebih banyak tekanan pada nilai baru. Rumus dibawah merupakan persamaan dari metode tersebut.

$$
M=\frac{\sum(\text { bobot periode } n)(\text { permintaan periode } n)}{\sum \text { bobot }}
$$

\subsection{Ukuran Ketepatan Suatu Metode}

Ukuran ketepatan suatu metode dari teknik pemrakiraan bisnis atau Godness of Fit adalah seberapa baik model pemrakiraan dapat memprakirakan data yang telah diketahui. Misal, karena ada lingkungan yang berubah, maka prakiraan 
mungkin menyimpang. Penyimpangan metode yang dipakai hendaknya dapat diterima dalam arti dicari penyimpangan yang terkecil. Model dengan penyimpangan terkecil inilah yang setidak-tidaknya dapat dijadikan acuan untuk pemrakiraan (Nugroho J. Setiadi, SE., MM. : 2003)

Terdapat beberapa macam cara untuk menghitung ketepatan suatu pemrakiraan atau peramalan, diantaranya adalah sebagai berikut:

1. Mean absolute deviation (MAD)

Mean absolute deviation (deviasi absolut rerata) digunakan untuk mencari rata-rata dari kesalahan absolut selama beberapa periode (tidak diperhatikan tanda positif dan tanda negatif, artinya penyimpangan baik diatas maupun dibawah nilai rata-rata tetap dikatakan sebagai penyimpangan, sehingga nilai penyimpangan di-absolut-kan). Rumus dibawah merupakan persamaan untuk menghitung MAD.

$$
M A D=\frac{\sum \mid \text { aktual }- \text { peramalan } \mid}{n}
$$

2. Mean absolute percent (MAPE)

Mean absolute percent (kesalahan prosentase absolut rerata) digunakan untuk mencari kesalahan absolut setiap periode, dibagi dengan banyaknya nilai yang dipakai. Rumus dibawah merupakan persamaan untuk menghitung MAPE.

$$
\text { MAPE }=\frac{\sum\left(\frac{\text { devisa absolut }}{\text { nilai aktual }}\right) * 100}{n}
$$

\section{Perancangan Sistem}

\subsection{Gambaran Umum Sistem}

Sistem Informasi Jual Beli Toko Emas adalah sistem yang dibuat untuk kebutuhan toko emas dengan studi kasus toko emas majusari. Sistem informasi yang dibuat untuk meningkatkan kinerja toko dalam bagian stok barang, transaksi, laporan keuangan, dan prediksi penjualan. Dengan adanya sistem informasi ini diharapkan toko emas majusari dapat mengoptimalkan waktu untuk penjualan sehingga pegawai tidak diharuskan membuat laporan stok barang, transaksi dan keuangan. Prediksi penjualan bertujaan agar pemilik toko bisa memprediksi konsumen sehingga dapat berpengaruh pada persiapan toko untuk menyediakan stok barang dan transaksi.

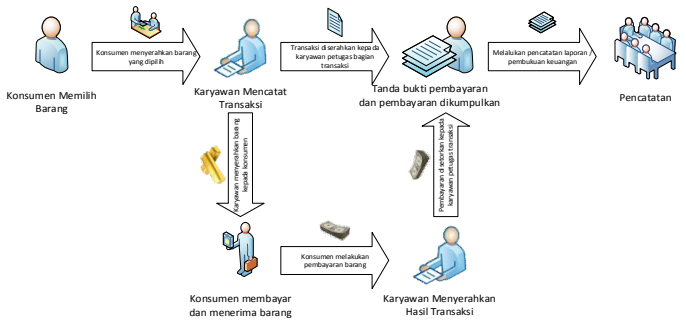

Gambar 2.1 Sistem yang berjalan saat ini

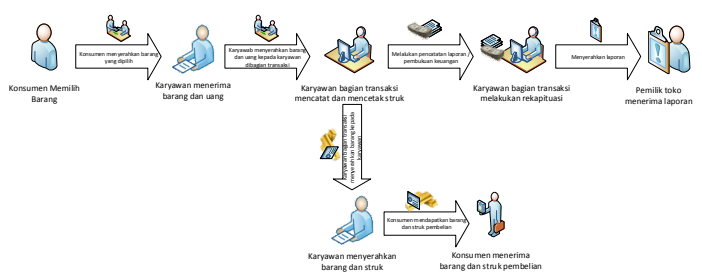

Gambar 2.2 Sistem yang akan dibuat

\subsection{Use Case Diagram}

Use case diagram merupakan pemodelan untuk kelakuan (behavior) sistem yang akan dibuat (Rosa A.S., 2013)

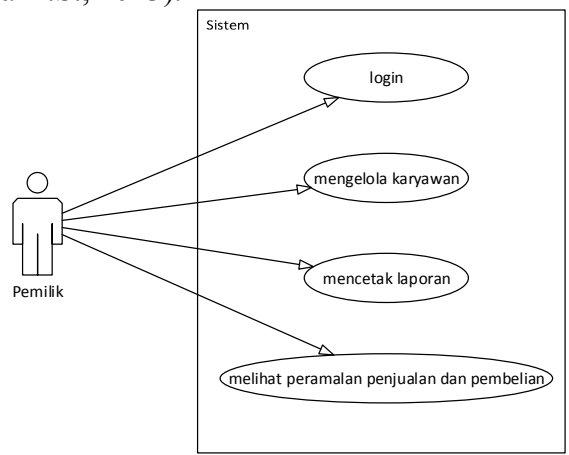

Gambar 2.3 Use case sistem pemilik toko

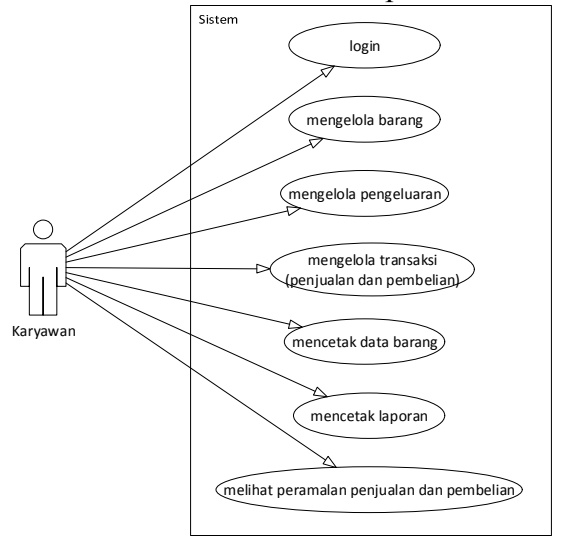

Gambar 2.4 Use case sistem karyawan

Pada gambar di atas terdapat 2 aktor yang terdiri dari:

- Pemilik toko

- Karyawan

Serta terdapat 11 kelakuan/aktivitas use case yang dapat dilakukan oleh aktor yang ada seperti pada Gambar 2.3 dan 2.4.

\subsection{Context Diagram}

DFD Level 0 atau context diagram biasa disebut sebagai diagram sistem inti (fundamental system model) atau biasa model konteks (context model). Arah panah dari aliran data menunjukkan aliran data berupa masukan (input) dan keluaran (output) ke dalam proses perangkat lunak yang dirancang sebagai berikut : 


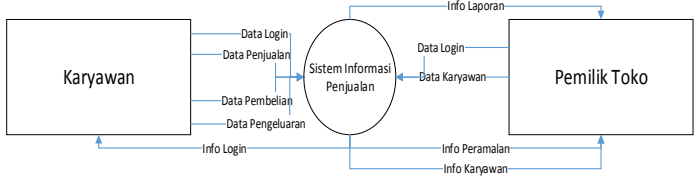

Gambar 3.4 Context Diagram

2.8 Algoritma Metode Weigted Moving Average

Algoritma merupakan alur berjalannya suatu proses pada sistem secara logis yang bertujuan untuk menyelesaikan masalah. Pada sistem peramalan ini terdapat proses utama yaitu proses perhitungan metode. Metode weighted moving average memiliki proses algoritma sebagai berikut:

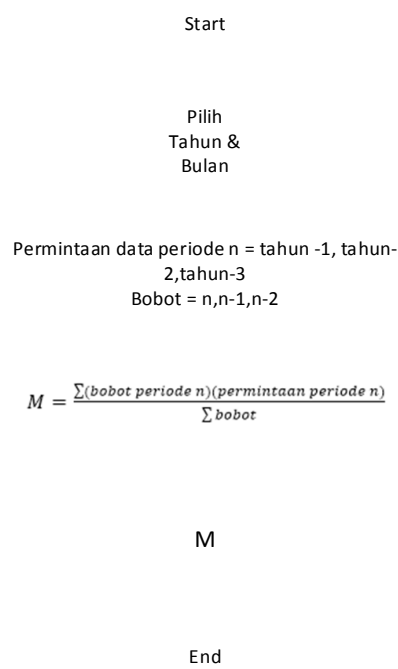

Gambar 3.5 Algoritma metode weighted moving average

\section{Implementasi}

\subsection{Implementasi Basis Data}

Implementasi basis data dilakukan sesuai dengan perancangan yang telah dibuat.

Pada basis data aplikasi ini terdapat 7 tabel, antara lain tabel pengeluaran, karyawan, pembelian, barang, penjualan, master_number, dan data.

\subsection{Implementasi Program}

Implementasi program yaitu tampilan hasil dari penerapan sistem yang telah dibuat, sesuai dengan perancangan yang telah dilakukan dengan hasil berupa tampilan aplikasi sebagi berikut:

Implementasi Sistem Informasi Penjualan dan Peramalan Jual Beli ini dilakukan dengan bahasa pemrograman VB.Net.

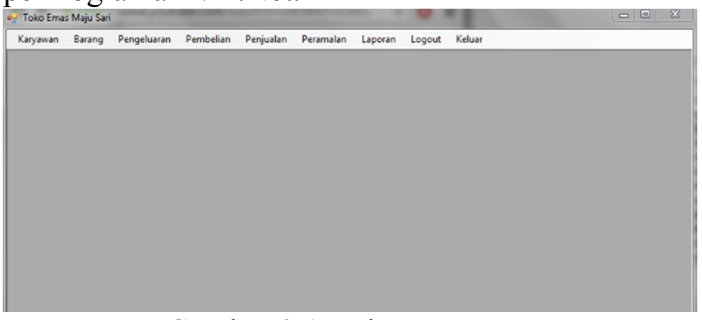

Gambar 3.1 Halaman utama

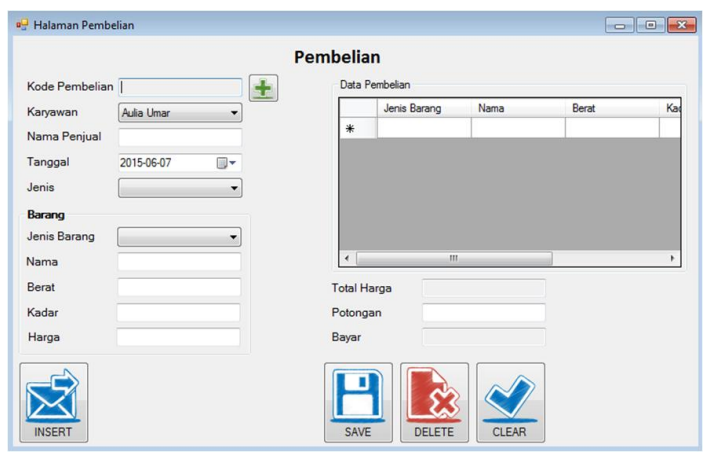

Gambar 3.2 Halaman pembelian

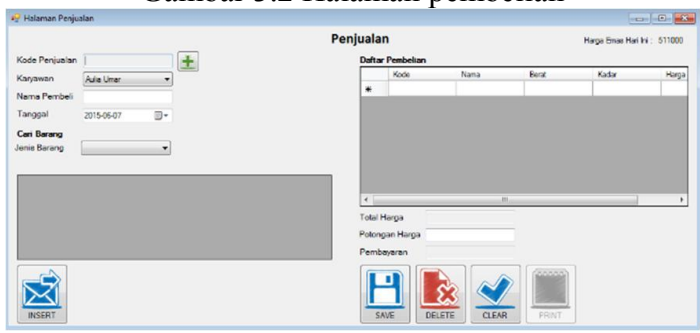

Gambar 3.3 Halaman penjualan

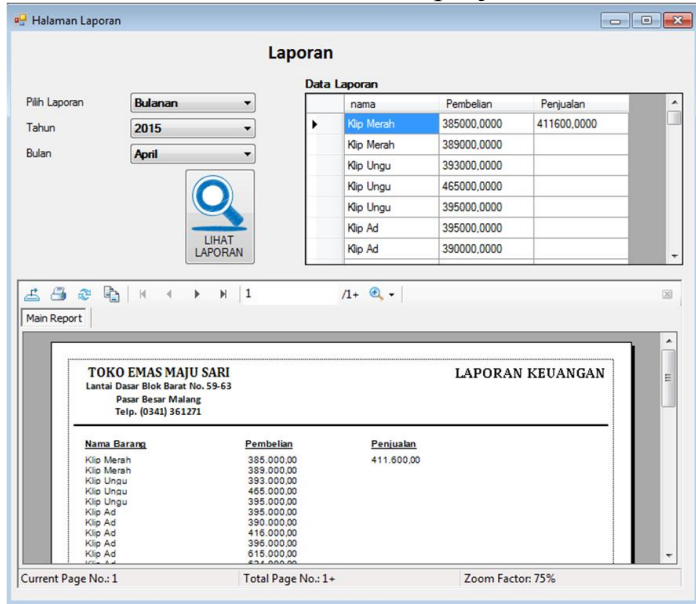

Gambar 3.4 Halaman laporan keuangan

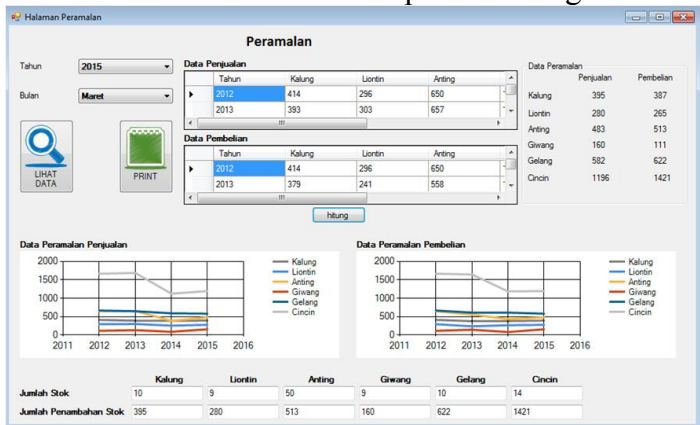

Gambar 3.5 Halaman peramalan

\section{Pengujian dan Pembahasan}

Pengujian pada sistem ini meliputi beberapa jenis pengujian, yaitu pengujian fungsional, pengujian metode den pengujian kinerja sistem. 


\subsection{Pengujian Fungsional}

Untuk menguji kinerja aplikasi dibutuhkan suatu pengujian sistem, yaitu pengujian fungsionalitas aplikasi. Pengujian ini dilakukan dengan cara menjalankan setiap fitur dalam aplikasi dan melihat apakah hasilnya sudah sesuai dengan yang seharusnya. Menurut pengujian sistem yang telah dilakukan, fungsi-fungsi dalam sistem ini telah berjalan sesuai perencanaan

\subsection{Pengujian Metode}

Pada pengujian weighted moving average, penulis melakukan peramalan dengan jangka waktu 4 bulan dengan 6 jenis barang yang berbeda. Pengujian menggunakan MAD dan MAPE untuk mengetahui nilai penyimpangan dari peramalan.:

Tabel 4.1 pengujian MAD dan MAPE

\begin{tabular}{|l|r|r|r|r|}
\hline \multirow{2}{*}{ Jenis } & \multicolumn{2}{|c|}{ Pembelian } & \multicolumn{2}{c|}{ Penjualan } \\
\cline { 2 - 5 } & MAD & \multicolumn{1}{c|}{ MAPE } & \multicolumn{1}{c|}{ MAD } & \multicolumn{1}{c|}{ MAPE } \\
\hline Kalung & 0,5 & 0,068693 & 9,5 & 2,242901 \\
\hline Liontin & $-18,5$ & $-7,45226$ & 18,25 & 6,982548 \\
\hline Anting & 107 & 16,38865 & 193,75 & 27,81958 \\
\hline Giwang & 50,75 & 28,0223 & 48,5 & 28,1918 \\
\hline Gelang & $-36,25$ & $-6,09541$ & -7 & $-1,22463$ \\
\hline Cincin & 286,75 & 16,63651 & 313,75 & 17,84354 \\
\hline
\end{tabular}

Nilai MAD dan MAPE yang dihasilkan pada pembelian jenis barang kalung paling kecil dibandingkan dengan jenis barang yang lain. Pada penjualan jenis barang gelang memiliki nilai MAD dan MAPE paling kecil dibandingkan jenis barang yang lain.

\subsection{Pengujian Kinerja Sistem}

Pada bagian ini akan dilakukan analisa dengan membandingkan seberapa membantukah sistem yang dikembangkan bagi user apabila diterapkan pada toko emas Maju Sari. Maka dilakukan presentasi kepada pemilik toko dan pegawai di toko emas Maju Sari Malang kemudian dilakukan voting sejauh mana aplikasi ini dapat meningkatkan kinerja toko. Terdapat 4 kriteria dalam penilaian ini, yaitu:

1. Kemudahan pengoperasian sistem.

2. Proses transaksi penjualan dan pembelian.

3. Proses pembuatan laporan keuangan.

4. Proses peramalan jual beli.

Kemudian dibuat 5 kategori penilaian, yaitu baik sekali $=4$, baik $=3$, cukup $=2$, kurang $=1$, dan sangat kurang $=0$. Sehingga menghasilkan tabel pengujian sebagai berikut:

Tabel 4.2 Table kuesioner pengujian performa kinerja sistem

\begin{tabular}{|c|r|r|r|r|}
\hline \multirow{2}{*}{ Responden } & \multicolumn{5}{|c|}{ Kriteria } \\
\cline { 2 - 5 } & \multicolumn{1}{|c|}{1} & \multicolumn{1}{|c|}{2} & \multicolumn{1}{c|}{3} & \multicolumn{1}{c|}{4} \\
\hline 1 & 4 & 4 & 4 & 2 \\
\hline 2 & 3 & 4 & 4 & 2 \\
\hline 3 & 4 & 3 & 4 & 2 \\
\hline 4 & 3 & 3 & 4 & 4 \\
\hline 5 & 3 & 2 & 4 & 3 \\
\hline 6 & 4 & 4 & 4 & 3 \\
\hline
\end{tabular}

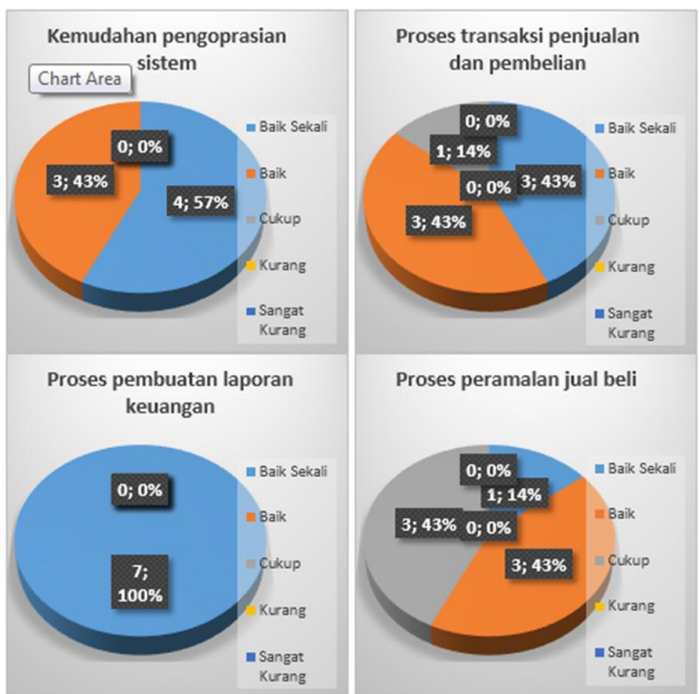

Gambar 4.4 Grafik Analisa Kuisiener Pengujian Performa Sistem

Dari Gambar Grafik 4.4 dapat disimpulkan dari pemberian nilai 7 responden didapati bahwa sistem ini sudah terbukti memenuhi syarat dari pihak toko emas Maju Sari yang berimbas pada peningkatan performa kinerja pegawai dan proses transaksi.

\section{Kesimpulan dan Saran}

\subsection{Kesimpulan}

Berdasarkan pembahasan pada bab 1 hingga 6 dapat ditarik beberapa kesimpulan, yaitu:

a. Hasil pengujian menunjukkan bahwa perancangan sistem telah menghasilkan sistem yang dapat membantu serta memudahkan pemilik toko dan karyawan dalam proses penjualan dan pembelian pada toko emas. Sistem yang diharapkan sudah memenuhi fitur-fitur yang diperlukan dalam proses transaksi pada toko, diantaranya: pencatatan karyawan, pengeluaran, pengecekan barang, pembelian dan penjualan.

b. Sistem telah berhasil memberikan laporan keuangan yang sebelumnya pencatatan dan perhitungan dilakukan secara manual. Laporan keuangan bisa dilihat dan dicetak dengan cepat pada saat penutupan toko. Laporan dibedakan dalam periode harian, bulanan, dan tahunan.

c. Sistem bisa membuat peramalan penjualan dan pembelian pada bulan yang ditentukan dengan mengacu pada data sebelumnya.

d. Dari peramalan penjualan dan pembelian, sistem secara otomatis menentukan jumlah stok barang yang harus ditambahkan pada bulan tersebut dengan tingkat keberhasilan yang sudah diuji coba pada bab V. 


\subsection{Saran}

Berdasarkan penelitian ini, ada beberapa hal yang disarankan yaitu:

a. Pada pengujian peramaln penjualan dan pembelian menunkukkan nilai penyimpangan yang tinggi. Maka bisa dibandingkan dengan metode yang lain sehingga menemukan nilai paling rendah dari beberapa metode.

b. Pada sistem ditambahkan fitur absensi karyawan sehingga pada laporan keuangan bisa melihat gaji karyawan dalam periode satu bulan.

\section{Daftar Pustaka:}

Anggita Puspitasari, 2012. "Ramalan Impor Produk Elektronik di Indonesia". Jurnal Ilmiah Universitas Gunadarma, Vol 3 : 14-26.

Baroto T. 2002. Perencanaan dan Pengendalian Produksi. Jakarta: Ghalia Indonesia.

Budi Sutedjo. 2002. Perencanaan \& Pembangunan Sistem Informasi. Yogyakarta: Andi.

C. Efisitek dan R. Fikriansyah. 2009. Dasar Pemrogaman VB.Net 2008. Jakarta: Restu Agung.

Francisca Adelyna, 2011. "Peranan Sistem Informasi Akuntansi Terhadap Pengendalian Intern Aktivitas Pembelian Bahan Baku Guna Mencapai Penyerahan Bahan Baku yang Tepat Waktu", Akurat Jurnal Ilmiah Akuntansi, No 06.
Gaspersz, Vincent. 2002. Production Planning and Inventory Control. Jakarta: PT. Gramedia Pustaka Utama.

Ilsan Nur, 2011. "Peramalan Permintaan dan Perencanaan Produksi dengan Mempertimbangkan Special Event di PT. CocaCola Bottling Indonesia”. Jurnal Teknologi dan Manajemen Informatika, Vol 6 : No. 1.

Kusrini. 2007, Membangun SIA dengan Visual Basic \& Microsoft SQL Server. Yogyakarta: Andi.

Lilis Puspitawati. 2011. Sistem Informasi Akuntansi. Yogyakarta: Graha Ilmu.

Purwoko, 2010. "Perancangan Sistem Informasi Akuntansi Pembelian dan Persediaan", CommIT, Vol 4 : 68-76.

Rochmawati Daud, 2014. "Pengembangan Sistem Informasi Akuntansi Penjualan dan Penerimaan Kas Berbasis Komputer pada Perusahaan Kecil”. Jurnal Manajemen dan Bisnis Sriwijaya, Vol 12 : 18-28.

Soeparno W. 2009. Analisis Forecasting dan Keputusan Manajemen. Jakarta: Salemba Empat.

Subayo Pangestu. 1986. Forecasting: Konsep dan Aplikasi.Yogyakarta : BPFE.

Yosep Yonhy, 2013. "Metode Trend Non Linear Untuk Forecasting Jumlah Keberangkatan Tenaga Kerja Indonesia Di Kantor Imigrasi Kelas II Kabupaten Nunukan", Jurnal Eksponensial, Vol 4 : No. 1. 